\title{
Soroprevalência de mormo, anemia infecciosa equina e brucelose do cavalo baixadeiro*
}

\section{The seroprevalence of glanders, equine infectious anemia and brucellosis of equine race "baixadeiro"}

\author{
Daniel Praseres Chaves, ${ }^{* *}$ Danilo Rodrigues Barros Brito, ${ }^{* *}$ Ana Clara Gomes dos Santos, ${ }^{* *}$ \\ Juliana Francisca Rocha Vaz, ${ }^{* *}$ Adriana Raquel Anunciação**
}

\begin{abstract}
Resumo
Visando subsidiar medidas de controle e prevenção das doenças infecciosas no cavalo "baixadeiro", criado na baixada ocidental maranhense, foram analisadas 415 amostras de soro sanguíneo pelas técnicas de imunodifusão em gel de ágar, fixação de complemento e antígeno acidificado tamponado para diagnóstico de anemia infecciosa equina, mormo e brucelose, respectivamente. Os casos positivos para mormo foram submetidos à maleinização pelo serviço oficial de defesa agropecuária e os animais reagentes para brucelose foram reexaminados pela técnica do 2 mercaptoetanol. Encontraram-se 81 (19,51\%) animais positivos para AIE, dois $(0,48 \%)$ para mormo e quatro $(0,96 \%)$ para brucelose. Dentre os animais com AIE, $41,97 \%$ eram machos e $58,03 \%$ fêmeas, $7,40 \%$ tinham entre 13 e 24 meses, 32,10\% entre 25 a 48 meses e 60,50\% acima de 48 meses de idade. A maior frequência de AIE foi observada em fêmeas e animais com idade superior a 48 meses. A anemia infecciosa equina é, sem dúvida, a enfermidade de maior impacto sobre os equídeos no Brasil, mas o mormo deve ser uma constante preocupação dos órgãos de defesa agropecuária, não devido ao número de casos, mas porque é uma zoonose com elevada morbidade e letalidade. A brucelose equina merece preocupação em virtude da debilidade orgânica que provoca nos animais, pelos prejuízos decorrentes da eutanásia dos equinos infectados, além de constituírem fonte de infecção para outras espécies domésticas, inclusive, para o homem.
\end{abstract}

Palavras-chave: diagnóstico, doenças infecciosas, equinos.

\begin{abstract}
Aiming to support measures for control and prevention of infectious diseases in "Baixadeiro" horse, we analyzed 415 blood serum samples by the techniques of agar gel immunodiffusion, complement fixation and buffered acidified antigen for the diagnosis of equine infectious anemia, glanders and brucellosis, respectively. The cases positive for glanders underwent maleinização by the official service of agricultural health and reagents animals for brucellosis were re-examined by the technique of 2-mercaptoethanol. Met $81(19.51 \%)$ animals positive for EIA, two (0.48\%) for glanders and four $(0.96 \%)$ for brucellosis. Among the animals with EIA, $41.97 \%$ were males and $58.03 \%$ females, $7.40 \%$ were between 13 and 24 months, $32.10 \%$ from 25 to 48 months and 60.50 $\%$ over 48 months old. The EIA was more frequently observed in female animals aged more than 48 months. Equine infectious anemia is undoubtedly the greatest impact on disease of equines in Brazil, but glanders should be a constant concern of the organs of agricultural defense, not because of the number of cases, but because it is a zoonotic disease with high morbidity and lethality. Equine brucellosis deserves concern because the organic weakness that causes the animals, for damages arising from the euthanasia of infected horses, as well as being a source of infection to other household, even for the man species.
\end{abstract}

Keywords: Horses, diagnoses, infeccion diseases.

\section{Introdução}

Na Baixada Maranhense destaca-se uma raça de cavalos nativos, denominada pela população local de "baixadeiro", caracterizada pela rusticidade, força para o trabalho e resistência a vastas áreas planas de campos alagados no período chuvoso e solo com rachaduras no período seco. Esse grupamento racial apresenta pequeno porte e pelagem predominantemente tordilha e castanha, sendo o resultado do cruzamento de raças trazidas da península Ibérica, provavelmente dos cavalos garrano e berbere (Gazolla et al., 2009).
Estima-se que a população de equinos tipicamente "baixadeiros" esteja em torno de quatro mil exemplares, que influenciam de maneira marcante as condições socioeconômicas dos habitantes da baixada maranhense (Serra, 2004). De acordo com Mariante et al. (2008), o cavalo "baixadeiro" está inserido no Programa Brasileiro de Conservação de Recursos Genéticos Animal.

Dentre as enfermidades dos equídeos, a Anemia Infecciosa Equina (AIE) se destaca como uma das mais prevalentes em todo o Brasil. Trata-se de uma doença infectocontagiosa de etiologia viral, limitada a equinos, asininos e muares (Carlson,

*Recebido em 20 de maio de 2014 e aceito em 23 de março de 2015

**Universidade Estadual do Maranhão - Centro de Ciências Agrárias - Departamento de Patologia - São Luís, Maranhão, Brasil.

Autor para correspondência: daniel@cernitas.com.br

***Instituto Federal do Maranhão; Laboratório de Sanidade Animal; São Luís, Maranhão, Brasil. 
2006). A maioria dos animais infectados não demonstra nenhum sinal clínico, porém, pode-se observar febre intermitente, trombocitopenia, anemia leve a moderada, anorexia, depressão, fraqueza, icterícia, edemas, petéquias nas mucosas e esplenomegalia (Craigo et al., 2009).

O Mormo é uma doença infectocontagiosa que acomete equinos, asininos, muares, carnívoros e humanos e resulta de infecção pela bactéria Burkholderia mallei (Al-Ani e Roberson, 2007). A transmissão ocorre principalmente através do contato com secreções respiratórias ou de feridas de animais infectados (OIE, 2008). Os sinais clínicos incluem febre, tosse, secreção nasal de aspecto purulento, abscessos subcutâneos, linfangite, edema e úlceras nos membros (Mota, 2006).

A brucelose é uma doença infectocontagiosa, com potencial zoonótico, incomum em equinos e é causada predominantemente pela Brucella abortus. A doença em equinos não é caracterizada por transtornos reprodutivos como em outras espécies domésticas. Lesões abscedantes em região cervical, bursas, tendões e articulações são as principais manifestações clínicas (Ribeiro et al., 2008).

Devido à importância que essas doenças têm para a equinocultura e seu desenvolvimento em uma região, objetivouse determinar soroprevalência de mormo, anemia infecciosa equina e brucelose no cavalo "baixadeiro" visando subsidiar medidas de controle e prevenção.

\section{Material e métodos}

Na mesorregião norte maranhense encontra-se a microrregião da baixada maranhense ( $01^{\circ} 59^{\prime}-04^{\circ} 00^{\prime} \mathrm{S}$; $44^{\circ} 00^{\prime}-45^{\circ} 33^{\prime} \mathrm{W}$ ), com uma área total de $17.579,366 \mathrm{~km}^{2}$ e população de 518.241 habitantes, distribuída em 21 municípios (IBGE, 2006). Banhada pelos rios Mearim, Pindaré, Pericumã e Aurá, a região é caracterizada por extensos conjuntos de lagos e lagoas naturais, denominados também de pantanal amazônico, que incorpora uma complexa interface de ecossistemas, abrigando rica fauna e flora aquática e terrestre (Pinheiro et al., 2005).

Foram utilizados 415 equinos entre machos e fêmeas com idade variando de sete meses a 10 anos, todos pertencentes ao grupamento racial "baixadeiro" encontrados nos municípios de Pinheiro, Arari, Anajatuba, Matinha, Viana e São João Batista pertencentes a área de proteção ambiental da Baixada Maranhense, no período de 2011-2013.

Amostras de $10 \mathrm{ml}$ de sangue foram obtidas de cada animal a partir de punção da jugular externa em frascos sem anticoagulante. Após centrifugação, o soro sanguíneo foi congelado e transportado em caixas isotérmicas ao Laboratório de Imunodiagnóstico do Centro de Ciências Agrárias da Universidade Estadual do Maranhão para realização do exame de Brucelose e para o laboratório Cernitas, pertencente à Rede Nacional de Laboratórios Agropecuários do Ministério da Agricultura Pecuária e Abastecimento (MAPA) para exames de AIE e Mormo.

O diagnóstico sorológico de AIE foi realizado por meio da técnica de imunodifusão em gel de ágar (IDGA). A técnica de Fixação de Complemento foi utilizada para diagnóstico sorológico de Mormo, sendo que os animais positivos foram submetidos à maleinização pelo serviço oficial de defesa sanitária animal. Para o diagnóstico de brucelose realizou-se a técnica do antígeno acidificado tamponado (AAT) como triagem. As amostras positivas pelo AAT foram submetidas ao teste do 2 Mercaptoetanol (2ME).

A amostra foi calculada considerando-se a estimativa média da prevalência de AIE em outros estados, que foi de $22 \%$ (Silva et al., 1999; Dias, 2000; Heinemann et al., 2002), tendo como unidades de análise os equídeos da baixada maranhense. $O$ cálculo foi feito por meio do programa Epi Info 3.5.3, utilizandose os seguintes parâmetros: $\mathrm{N}=4000$ (número aproximado de cavalos "baixadeiros"), com uma prevalência estimada de 0,22 ; precisão de 0,05 e nível de confiança de 0,95 . O amostral obtido foi de 248 animais, sendo que foram coletadas amostras de 415 animais.

\section{Resultados e discussão}

De 415 amostras examinadas, 81 (19,51\%) foram positivas para AIE, duas $(0,48 \%)$ para mormo no teste de $\mathrm{FC}$, sendo que ambos se mostraram negativos à maleinização e quatro $(0,96 \%)$ para brucelose, confirmados pelo $2 \mathrm{ME}$ (Tabela 1). Dentre os animais com AIE, 41,97\% eram machos e 58,03\% fêmeas, $7,40 \%$ tinham entre 13 e 24 meses, $32,10 \%$ entre 25 a 48 meses e $60,50 \%$ acima de 48 meses de idade. A maior frequência de AIE foi observada em fêmeas e animais com idade superior a 48 meses (Tabela 2).

Tabela 1: Soroprevalência de AIE, mormo e brucelose em equinos do grupamento racial cavalo "baixadeiro", criados nos municípios de Pinheiro, Arari, Anajatuba, Matinha, Viana e São João Batista, Maranhão, Brasil

\begin{tabular}{llll}
\hline Enfermidade & Negativo & Positivo & Total \\
\hline Mormo & $413(99,52 \%)$ & $2(0,48 \%)$ & $415(100 \%)$ \\
AIE & $334(80,48 \%)$ & $81(19,51 \%)$ & $415(100 \%)$ \\
Brucelose & $411(99,04 \%)$ & $4(0,96 \%)$ & $415(100 \%)$ \\
\hline
\end{tabular}

Tabela 2: Equinos "baixadeiros" soropositivos para AIE de acordo com o sexo e a faixa etária

\begin{tabular}{llll}
\hline & Negativo & Positivo & Total \\
Macho & $47(58,03 \%)$ & $34(41,97 \%)$ & $81(100 \%)$ \\
Fêmea & $34(41,97 \%)$ & $47(58,03 \%)$ & $81(100 \%)$ \\
$>13$ a 24 meses & $75(92,60 \%)$ & $6(7,40 \%)$ & $81(100 \%)$ \\
$>25$ a 48 meses & $55(67,90 \%)$ & $26(32,10 \%)$ & $81(100 \%)$ \\
$>48$ meses & $32(39,50 \%)$ & $49(60,50 \%)$ & $81(100 \%)$ \\
\hline
\end{tabular}

A taxa de positividade para AIE encontrada em equinos na baixada maranhense pode ser justificada pelo fato de que os animais são mantidos em sistema ultra extensivo, sem assistência técnica e sem a realização de exames periódicos e nem medidas de controle. Estes resultados se assemelham aos de Heinemann et al. (2002), que encontraram uma soroprevalência de $17,71 \%$ num total de 96 equinos pesquisados no município de Uruará-PA. Dias (2000) também encontrou razoáveis taxas de animais soropositivos no estado do Pará: $28,53 \%$ na llha de Marajó, 10,70\% em São Miguel do Guamá, $17,00 \%$ em Santa Maria do Pará e $25,00 \%$ em Paragominas. No Acre também foram observadas altas frequências de animais 
positivos, sendo $22,9 \%$ na Bacia do Alto Juruá; $12,4 \%$ em Alto Acre e $9,5 \%$ na Alta Bacia do Purus (Santos et al., 2001). Segundo este autor, esses resultados se justificam por essas áreas apresentarem como principal atividade econômica o extrativismo vegetal da seringueira e da castanha do Brasil, as quais utilizam os equídeos como o único meio de locomoção.

Em estudo realizado no pantanal mato-grossense, região que se assemelha à baixada maranhense pelo fato de ser uma planície estacionalmente inundável, Silva et al. (1999) encontraram $34,1 \%$ de AIE nos animais de trabalho, com um convívio mais próximo do homem e 5,6\% naqueles criados extensivamente, nos quais a transmissão se dá quase que exclusivamente por meio de vetores.

Por outro lado, em outras regiões do Brasil a AIE aparentemente está mais controlada, com prevalência em patamares mais baixos que os achados nesta pesquisa, tais como sul de Minas Gerais com 1,1\% (Almeida et al., 2006); Bahia 5,9\% (Guimarães et al., 2011) e Distrito Federal 1,81\% (Moraes, 2011).

Em relação à idade e sexo, notou-se que os resultados deste trabalho se assemelham a outras investigações epidemiológicas sobre AIE, considerando-se que, provavelmente, a maior exposição ao vetor faz com que as taxas mais elevadas de reagentes estejam entre os animais mais velhos, não havendo diferenças significativas entre machos e fêmeas que estejam igualmente expostos. Heidmann et al., (2012) em estudo retrospectivo realizado no sul do Pará, observaram que a maior frequência de animais positivos ocorreu em idade adulta, a partir de seis anos $(14,81 \%)$ e $9,68 \%$ naqueles com cinco anos ou menos. Moraes (2011) trabalhando com animais de haras, verificou que não foi possível demonstrar associação entre positividade e sexo e que a doença afetou machos e fêmeas na mesma magnitude. Este autor afirmou ainda, diferentemente dos achados deste trabalho, que não foi possível afirmar que havia associação entre a idade e os casos positivos.

A Brucelose em equinos tem apresentado baixa taxa de ocorrência em todo o território nacional, o que não diferiu desta pesquisa. Arruda et al. (2012), em estudo realizado em 857 amostras de equinos no estado da Paraíba, encontraram apenas $5(0,6 \%)$ animais positivos. Oliveira et al. (1973) encontraram $5,3 \%$ de reagentes em 75 equinos em Santa Maria, RS. Langoni e Silva (1997) detectaram $0,82 \%$ de animais reagentes em 734

\section{Agradecimentos}

À FAPEMA, pelo apoio financeiro.

\section{Referências}

ACHA, P.N.; SZYFRES B.. Zoonosis y enfermidades

transmisibles comunes al hombre y a los animales. 3. ed.

Washington: Organización Panamericana de la Salud, 2003, 28$56 \mathrm{p}$.

AL-ANI, F.K.; ROBERSON. J.. Glanders in horses: a review of the literature. Veterinarski Arhiv, v. 77, p. 203-218, 2007.

ALMEIDA, C.A.S.; RIBEIRO, M.G.; MEGID, J.; VASCONCELLOS, A.S.; BORGES, A.S; BONESI, G. Ocorrência de aglutininas anti-Brucella abortus em soros de equídeos de abatedouro. In: CONGRESSO NACIONAL DE SAÚDE PÚBLICA VETERINÁRIA, 2. 2007. Anais... Fortaleza: CNSPV, 2007. equinos procedentes do estado de São Paulo. Almeida et al. (2007) avaliaram 875 amostras de soro de equinos abatidos nas regiões Sul e Sudeste e observaram 15 (2\%) animais reagentes.

Provavelmente, a presença de equinos "baixadeiros" com anticorpos anti-Brucella, deve-se ao convívio com outras espécies, pois ainda que o mecanismo de transmissão da brucelose em equinos não esteja bem esclarecido, considera-se que a infecção seja resultante da coabitação com outros animais domésticos, em especial bovinos, bubalinos e suínos, visto que os equinos compartilham da infecção preferencialmente por $B$. abortus (Acha e Szyfres, 2003) e, secundariamente, por B. suis (Cook e Kingston, 1988; Acha e Szyfres, 2003). Esta bactéria pode permanecer viável por vários meses em fetos, pastos e água contaminada, favorecendo a manutenção do patógeno no ambiente e a endemicidade nos plantéis (Rosa et al., 2006).

São poucos os trabalhos sobre mormo, mas é consenso entre os pesquisadores que se trata de uma doença reemergente no Brasil com o aparecimento de focos em diversos estados do Nordeste e Sudeste. A baixa ocorrência de animais reagentes ao teste de Fixação do Complemento nesta pesquisa pode ser justificada pelo fato de que o cavalo "baixadeiro" é criado solto em grandes áreas de campo, com pouco ou nenhum manejo, pois segundo Langenegger et al. (1960), a transmissão está diretamente relacionada com o manejo, incriminando os estábulos coletivos como um dos principais focos de transmissão.

A anemia infecciosa equina é, sem dúvida, a enfermidade de maior impacto sobre os equídeos, mas o mormo deve ser uma constante preocupação dos órgãos de defesa agropecuária, não devido ao número de casos, mas porque é uma zoonose com elevada morbidade e letalidade. A brucelose em equinos e o mormo merecem preocupação em virtude da debilidade orgânica que provoca nos animais, pelos prejuízos decorrentes da eutanásia dos equinos infectados, além de constituírem fonte de infecção para outras espécies domésticas e, inclusive, para o homem.

\section{Conclusão}

Registra-se a ocorrência de anemia infecciosa equina, mormo e brucelose em equinos da Baixada Maranhense, sendo o primeiro relato dessas enfermidades no cavalo baixadeiro, indicando a necessidade de prevenção e controle.
ALMEIDA, V.M.A.; GONÇALVES, V.S.P.; MARTINS, M.F. Anemia infecciosa equina: prevalência em equídeos de serviço em Minas Gerais. Arquivo Brasileiro de Medicina Veterinária e Zootecnia, v. 58, n. 2, p. $141-148,2006$.

ARRUDA, F.R.; SILVA, M.H.; SOARES FILHO, P.M.; CAMPOS, A.C.; AZEVEDO, E.O. Medicina Veterinária, v. 6, n. 1, p. 7-10, 2012.

aBRASIL 2004. Ministério da Agricultura, Pecuária e abastecimento. Departamento de Defesa Animal. Instrução normativa $n^{\circ} 45$ de 16 de junho de 2004. Brasília.

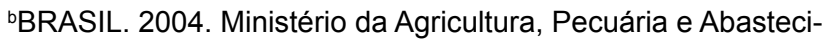
mento. Instrução normativa $\mathrm{n}^{\circ} 24$ de 05 de abril de 2004. Brasília. 
BRASIL. 2006. Ministério da Agricultura, Pecuária e Abastecimento. Instrução normativa $n^{\circ} 41$ de 28 de novembro de 2006. Brasília.

CARLSON, G. P. Doenças dos sistemas hematopoiético e hemolinfático. In: Smith BP, editor. Medicina interna de grandes animais. 3. ed. Barueri: Editora Manole, 2006, p.1039-1084.

COOK, D.R.; KINGSTON, G.C. Isolation of Brucella suis biotype 1 from a horse. Australian Veterinary Journal, v. 65, p. 162-163, 1988.

CRAIGO, J.K.; BARNES, S.; ZHANG, B.; COOK, S.; HOWE, L.; ISSEL, C.J.; MONTELARO, R.C. An EIAV field isolate reveals much higher levels of subtype variability than currently reported for the equine lentivirus family. Retroviroloy, v. 6 , n. 95, p. 1-12, 2009.

DIAS, H. L. T. Soroepidemiologia de cinco enfermidades infecciosas em equinos criados no Estado do Pará. 2000. 147 f. Tese (Doutorado) - Universidade Federal do Pará, Belém, 2000.

GAZOLLA, A.G.; SERRA, O.R.; LIMA, F.C. Pelagens do cavalo da raça baixadeira. In: REUNIÃO ANUAL DA SOCIEDADE BRASILEIRA DE ZOOTECNIA, 46., 2009. Anais... Maringá: RASBZ, 2009.

GUIMARÃES, L.A.; BEZERRA, R.A.; MENDONÇA, C.E.D.A. Prevalência do vírus da anemia infecciosa equina na mesorregião do sul baiano, Bahia, Brasil. Revista Brasileira de Medicina Veterinária, v. 33, n. 2, p. 1-5, 2011.

HEINEMANN, M.B.; CORTEZ, A.; SOUZA, M.C.C.; GOTTI, T.; FERREIRA, F.; HOMEM, V.S.F.; FERREIRA NETO, J.S.; SOARES, R.M.; SAKAMOTO, S.M.; CUNHA, M.S.; RICHTZENHAIN, L.J. Soroprevalência da anemia infecciosa equina, da arterite viral dos eqüinos e do aborto viral eqüino no município de Uruará, PA. Brasil. Brazilian Journal Veterinary Research and Animal Science, v. 39, n. 1, p. 50-53, 2002.

HEIDMANN, M.J.; FISCHER, V.L.; MANHEZZO, T.G.; SANTOS, J.D.; CASTRO, B.G. Estudo Retrospectivo da Anemia Infecciosa Equina na Região Centro-Sul do Pará, Brasil, 2007-2010. Revista Brasileira de Medicina Veterinária, v. 34, n. 3, p. 192-197, 2012.

INSTITUTO BRASILEIRO DE GEOGRAFIA E ESTATÍSTICA IBGE, 2006. Disponível em www.ibge.gov.br/2006. Acesso em: 12 de abril de 2013.

LANGONI, H.; SILVA, A.V. Comportamento sorológico de aglutininas anti-Brucella em soro de equídeos. Revista Brasileira de Medicina Veterinária, v. 19, p. 85-87, 1997.
LANGENEGGER, J.; DÖBEREINER, J.; LIMA, A.C. Foco de mormo (Malleus) na região de Campos, estado do Rio de Janeiro. Arquivo do Instituto Biológico Animal, v. 3, p. 91-108, 1960.

MARIANTE, A.S.; EGITO, A.A.; ALBUQUERQUE, M.S.M.; PAIVA, S.R.; RAMOS, A.F. Managing genetic diversity and society needs. Revista Brasileira de Zootecnia, v.37, suplemento especial, p. 127-136, 2008.

MORAES, D. D. A. Prevalência de mormo e anemia infecciosa equina em equídeos de tração do Distrito Federal. 2011. 85 f. Dissertação (Mestrado). Faculdade de Agronomia e Medicina Veterinária, Universidade de Brasília, Brasília, 2011.

MOTA, R.A. Aspectos etiopatológicos, epidemiológicos e clínicos do mormo. Veterinária e Zooteccnia, v. 13, n. 2, p. 117-124, 2006.

OIE. Manual of Diagnostic Tests and Vaccines for Terrestrial Animals 2008. Cap. 2.5.11. Disponível em: <http://www.oie.int/ eng/normes/mmanual/a_summry.htm>. Acesso em 11 ago. 2013.

OLIVEIRA, Q. C.; MOREIRA, V.S.; LIMA C.S. Brucelose em equinos. Revista Médica, v. 9, p. 93-106, 1973.

PINHEIRO, C.U.B.; SANTOS, V.M.; FERREIRA, F.R.R. Usos de subsistência de espécies vegetais na região da baixada maranhense. Amazônia: Ciência \& Desenvolvimento, v. 1, n. 1, p. 235-250, 2005.

RIBEIRO, M.G.; MOTTA, R.G.; ALMEIDA, C.A.S. Brucelose equina: aspectos da doença no Brasil. Revista Brasileira de Reprodução Animal, v. 32, n. 2, p. 83-92, 2008.

ROSA, I.; GONZALES, A.; REYES, G.I.; GUTIERREZ, F H.G. Prevalence of Brucella abortus antibodies in equines of a tropical region of México. Canadian Journal of Veterinary Research, v. 70, p. 302-304, 2006.

SANTOS, R.M.L.; REIS, J.K.P.; SANTOS, F.G.A.; OLIVEIRA, I.C.S. Frequência de anemia infecciosa em equinos no Acre, 1986 a 1996. Arquivo Brasileiro de Medicina Veterinária e Zootecnia, v. 53, n. 3, p. 310-315, 2001.

SERRA, O. R. Condições de manejo, preservação e caracterização fenotípica do grupamento genético equino baixadeiro, 2004. 84 f. Dissertação (Mestrado) - Universidade Estadual do Maranhão, São Luís, 2004.

SILVA, R. A. M. S.; DÁVILA, A. M. R.; ABREU, U. G. P. Equine viral diseases in Pantanal, Brazil. Studies carried out from 1990 to 1995. Revue d'Élevage et Medicine Véterinaire dês Pays Tropicaux, v. 52, p. 9-12, 1999. 